\title{
Does the Quality of Marriage in Women Get Affected by the Perceived Satisfaction While Communicating with their Spouses?
}

\author{
Dr. Sanchita Pakrashi ${ }^{1}$, Dr. Rituparna Basak ${ }^{2}$ \\ ${ }^{1}$ Consultant Psychologist, Kolkata, West Bengal, India \\ ${ }^{2}$ Assistant Professor, Department of Psychology, Muralidhar Girls College, Kolkata, West Bengal, India
}

\begin{abstract}
The study was conducted to understand empirically whether the wives in discordant marriage perceive more dissatisfaction while communicating with their spouses than that of the wives who are in harmonious marriages. Total numbers of subjects included were 160 among which the number of discordant wives and harmonious wives were 80 in each case belonging to the Bengali Hindu community from the different parts of the city of Kolkata, India with purposive sampling technique. The two groups were compared using the scales: 'Marital Quality Scale' (M.Q.S.) and 'Interpersonal Communication Satisfaction Inventory' (I.C.S.I..). 't - statistics' and correlation were conducted to analyze the data. Results showed that discordant and harmonious wives differed significantly in their quality of married life as well as in perception of communication satisfaction with their spouses. Poor marital quality was correlated with poor perception of communication satisfaction and vice versa.
\end{abstract}

Keywords: Perceived communication satisfaction, marital quality, harmonious wives, discordant wives

\section{Introduction}

'Marriage' is considered as the most intimate relationship and a socially supported union between two individuals with an apprehension of developing a stable and enduring relationship in order to build a strong family. The concept of marriage in Indian Hindu culture is somewhat different from other cultures on the ground of consideration as a sacramental bond which is indissoluble in nature. That is why the 'Hindu Code' (Hindu personal law in India) historically has not formally recognized marital dissolution (Goode, 1970; Holden, 2008; Parry, 2001). Considering the Indian literature it can be said that, marriages were largely developed around gender roles in the past, where the wife needed to take the responsibility of homemaking and child rearing and the husband were expected to support the family only economically. The rapid development and transformation of Indian society as well as the families over the past few decades have also changed the institution of marriage drastically. The family's major function has become relational rather than role fulfilling. There are no longer any hard and fast rules about the roles that each partner will play or even about the primacy of the relationship. In a recent study by Yadav \& Rekha (2018) it was found that the female participants of this new Indian era, were found to be equally accepting of their responsibility in marital life and viewing themselves as equal to males with respect to roles defined by the Indian society. Results also indicate mutual compatibility as an important domain for the success of marriage in life.

Besides these changes in role expectancies of Indian marriage, the concept of 'getting settled' through marriage is still unchanged, which somehow equals with 'being happy or satisfied'. The protective effects of marriage are happiness, satisfaction and emotional well being which can not be universally attained just by getting married, is still not accepted in the collective unconscious of Indian parents. 'Marriage does not make you happy; happy marriages make you happy', says Harvard professor of Psychology and happiness expert Daniel Gilbert (2006). Recent researches show that these 'Happy' or 'Unhappy' effects are conditional upon the quality of marriage. The quality of marital life involves multidimensional phenomena (Spainer \& Lewis, 1980) and there is no single, standardized measure of marital quality used across all studies (Bradbury, et al., 2000). Since marital relationship has a distinct culture specific component, aspects that are considered important measuring marital quality in the western or other countries may not be adequate for understanding the same in the Indian context. With the increasing interest and willingness to acknowledge sensitive marital problems in Indian context, researchers and clinicians are working on distinguishing healthy marital relationships from disturbed ones. The quality of marriage in Indian context were found to depend on a number of factors like understanding, feeling of rejection from spouse, satisfaction of sexual and security needs, affectional needs, feeling of despair, decision making ability, feeling of discontent, consideration of separation or divorce as an alternative, dominance, self-disclosure, trust and role functioning (Shah, 1995).

Both the lay people as well as the professional psychologists agree to a great extent that successful marriages or in other words, marriages with good qualities are built on effective communication. It is again considered that an effective communication as a means of conveying information with lesser ambiguity, enhances pleasure, facilitating adoption to the environment and minimization of feelings of pain. While after communicating, if the subsequent feeling tones of both

Volume 9 Issue 10, October 2020 


\section{International Journal of Science and Research (IJSR) ISSN: 2319-7064 \\ ResearchGate Impact Factor (2018): 0.28 | SJIF (2019): 7.583}

the communicators are positive, it is found to nurture their feelings of relationship satisfaction and the reverse is also true. In this sense, cumulative ongoing perceived satisfaction or dissatisfaction while communicating plays an important role in maintaining mutual adjustment between spouses (Hecht, 1978). A large body of research shows that absence of effective communication and disturbed communication between spouses lead to perceived dissatisfaction which in turn decrease marital quality gradually and lead to marital disharmony or discord.

Communication and satisfaction are correlated concurrently not only because communication predicts satisfaction but also because satisfaction predicts communication. During moment -to-moment clashes of interests in conflict situations, couples start communicating negatively or destructively, which leads to a negative feeling tone influencing their perceived feelings of dissatisfaction. Such cumulative ongoing burden of dissatisfaction for a longer period gradually damages the quality of relationship silently affecting the chances of further communication of pleasant quality. Same is true for the opposite too. Studies show, couples who communicate with more negativity in the first two years of marriage, report greater perceived unhappiness (or dissatisfaction) in their marriages after more than a decade, compared to couples who are more positive early on (Huston, Caughlin, Houts, Smith \& George, 2001). More negative communication predicts slower, not faster, declines in perceived satisfaction (Karney \& Bradbury, 1995).

Although research has demonstrated that marital dissolution among the Western populations depends on the marital quality and other factors including communication (Gotman, 1994; Amato \& Rogers, 1997; DeMaris, 2000), the same in Indian setting is quite unclear. Even less clear is whether a wife's perception of marital quality will be as influential as her husband's perception of marital quality (Jennings, 2014). In this view, the current researchers would try to explore whether the quality of marriage in women gets affected by the perceived satisfaction while communicating with their spouses in a local population in Kolkata, India. In other words, the purpose of the study is to understand empirically if the wives in harmonious marriage have better perception of satisfaction while communicating with their spouses as opposed to that of the wives in discordant marriage.

\section{Hypotheses of the study}

- H1: The perceived marital quality will be significantly different between the wives of discordant and harmonious groups.

- H2: There will be significant differences between the wives of discordant and harmonious groups in perception of communication satisfaction.

- H3: Perception of communication satisfaction will be significantly correlated with the perceived marital quality of both wives of discordant and harmonious marriage respectively.

\section{Methodology}

\subsection{Sampling}

The data have been collected from the wives belonging to both discordant and harmonious marriages from the middle class section of Bengali Hindu community with the inclusion and exclusion criteria stated below from the different parts of the city of Kolkata, India with purposive sampling procedure. Total numbers of subjects included were 160 among which the number of discordant wives and harmonious wives were 80 in each case.

\subsection{Instruments}

\section{Background Information Schedule}

A semi structured interview schedule was prepared to collect information on the background of the participants, for example, name, age, gender, residential address, telephone number, educational qualification, type of marriage, duration of marriage, number of children with their respective ages, type of family and Socio-Economic Status (including items like: occupation, number of family members, number of earning members in the family, approximate monthly income of the family, type of dwelling house and surroundings of the dwelling house).

Marital Quality Scale (M.Q.S. - Anisha Shah, 1995) is a 50item questionnaire used to assess the quality of marital life of the participants. They were asked to rate each statement related to the occurrence of certain situations in their married life and partner's attitude on a 4 - point rating scale ranging from 'usually - never'. The scale has 28 positively worded items and 22 negatively worded items. There are 12 factors present in the scale among which 5 factors have only positively worded items: Understanding, Satisfaction, Decision Making, Trust and Role Functioning. Factors of Rejection, Despair, Discontent, Dissolution Potential and Dominance only have negatively worded items. Factors of Affection and Self-disclosure consist of both positively and negatively worded items. The total score is summation of scores obtained on individual items. The scale provides two types of scores - total scores and scores on 12 factors of the scale. The lowest possible score being 50 and the highest possible score being 200. In the scale, the higher the score the poorer is the marital quality. The median split of the scale being 125 , scores above it, denotes poorer marital quality and scores below it reflects better marital quality. The scale had high internal consistency (coefficient alpha $=0.98$ ).

Interpersonal Communication Satisfaction Inventory (Hecht, 1978) is a 19 items Likert type questionnaire, used to measure perceived satisfaction or dissatisfaction from the communication with the respective spouses. Participants were to use a 7 - point 'agree - disagree' scale to rate the degree to which each statement expressed the attitude of their spouses and their own personal feeling related. Score 1 indicated 'complete agreement' with the statement and score 7 indicated 'complete disagreement' with the statement. The questionnaire

Volume 9 Issue 10, October 2020 


\section{International Journal of Science and Research (IJSR) \\ ISSN: 2319-7064 \\ ResearchGate Impact Factor (2018): 0.28 | SJIF (2019): 7.583}

was categorized as 'high' or 'low' by a median split of 57 . Higher score represented greater perceived satisfaction from communication. A modified and adapted version of Hecht's original inventory in Bengali (Prof, Dr. Indrani Mukherjee, Department of Applied Psychology, Calcutta University, India) had been used. Cronbach's Alpha Coefficient Reliability was 0.84 (Mitra \& Mukherjee). In the present study the Alpha Coefficient Reliability is found to be 0.97 .

\section{Variables and their operational definition}

\section{The Independent Variable (IV)}

\section{Perception of Communication Satisfaction}

It is the accumulation of day-to-day perception of feelings of satisfaction or dissatisfaction while communicating with the spouse.

\section{The Dependent Variable (DV)}

\section{Quality of Marriage}

It is the quality of one's marital life involving factors like understanding, feeling of rejection from spouse, satisfaction from sexual and security needs, affectional needs, feeling of despair, decision making ability, feeling of discontent, consideration of separation or divorce as an alternative, dominance, self-disclosure, trust and role functioning.

\section{The Relevant Extraneous Variables (REV)}

\section{Inclusion Criteria}

- Subject's (Ss') age (25 years to 45 years).

- Subject's gender - Female

- Educational qualification (Graduation and beyond).

- Socio Economic Status (all belonging to upper-middle and middle - middle section of Bengali community within the city of Kolkata, India. For the purpose of determining the socio-economic status of the subjects, L.J. Warner's Socioeconomic Status Index, 1960; methodology was applied here).

- Religion (Hinduism).

- Type of marriage (arranged or Love).

- Duration of marriage (at least 4 years).

- Type of family (nuclear or extended nuclear).

- Number of children (at least one child).

\section{Exclusion Criteria}

- Subjects with the previous diagnosis of mental retardation, epilepsy, psychoses and personality disorder.

- Subjects having inter-religion marriage, having more than one spouse, separated or divorced.

\section{Procedure}

In the first stage, the researchers explained the purpose of the study to the persons who came to seek professional help for rebuilding their relationship with their respective marital partners. After seeking the permission from each person and matching them with both inclusion and exclusion criteria, Marital Quality Scale was administered on them individually. The females who scored high in the scale were enlisted as the discordant wives. For the wives living in harmony in their respective marriages, the researchers contacted the familiar persons in their daily life (not having any manifested discord) who wanted to cooperate after knowing the purpose of the study and also who matched according to the inclusion and exclusion criteria. They were provided with the Marital Quality Scale separately and those who scored low in the scale were enlisted as the harmonious wives. The process took about more than six months to be finished. In the second stage, the persons, who were screened as both harmonious and discordant, were interviewed by administering tool booklets consisting of the background information schedule and the Interpersonal Communication Satisfaction Inventory (Hecht, 1978). The interview session for each participant was half an hour approximately on the basis of mutually convenient time. The entire interviewing the episode lasted for a little more than six months. Next, the responses were scored, tabulated and were kept ready for the application of statistical tools. The collected data was analyzed using Statistical Package for Social Sciences (SPSS).

\section{Results and Discussion}

At first the Means and Standard Deviations of the two groups, namely, Harmonious Wives and Discordant Wives, for both the variables (Marital Quality - DV \& Perception of Communication Satisfaction - IV) were computed. Then $t$ statistics was used for testing the significance of difference between the means of discordant and harmonious wives in each of the variables. To see whether the dependent and independent variables are correlated or not, Pearson Product Moment Correlation was done.

Table 1: Means, Standard Deviations \& $\mathrm{t}-$ ratios for the sub factors \& total score of Marital Quality Scale (MQS) of wives of both Discordant \& Harmonious groups

\begin{tabular}{|c|c|c|c|c|c|}
\hline \multirow[t]{2}{*}{$\begin{array}{c}\text { Variable } \\
\text { M.Q.S }\end{array}$} & \multicolumn{2}{|c|}{$\begin{array}{l}\text { Discordant } \\
\text { Wives } \\
(\mathrm{N}=80)\end{array}$} & \multicolumn{2}{|c|}{$\begin{array}{c}\text { Harmonious } \\
\text { Wives } \\
(\mathrm{N}=80)\end{array}$} & \multirow[t]{2}{*}{ t-ratio } \\
\hline & $\mathrm{M}$ & \begin{tabular}{|l|} 
SD \\
\end{tabular} & $\mathrm{M}$ & $\mathrm{SD}$ & \\
\hline Understanding & 21.60 & 5.19 & 9.09 & 2.94 & $18.77 * *$ \\
\hline Rejection & 29.66 & 4.95 & 17.66 & 4.88 & $15.46^{* *}$ \\
\hline Satisfaction & 13.77 & 4.10 & 6.82 & 1.84 & $13.83 * *$ \\
\hline Affection & 17.72 & 4.68 & 8.08 & 3.13 & $15.35 * *$ \\
\hline Despair & 6.42 & 1.52 & 3.65 & 1.20 & $12.79 * *$ \\
\hline Decision Making & 15.90 & 4.02 & 8.00 & 2.28 & $15.29 * *$ \\
\hline Discontent & 6.12 & 1.61 & 3.31 & 1.40 & $11.79 * *$ \\
\hline Dissolution Potential & 3.04 & 1.14 & 1.20 & .62 & $12.63 * *$ \\
\hline Dominance & 6.39 & 1.73 & 5.01 & 2.14 & $4.47 * *$ \\
\hline Self Disclosure & 8.28 & 2.47 & 4.07 & 1.39 & $13.29 * *$ \\
\hline Trust & 2.53 & 1.16 & 1.04 & .25 & $11.23 * *$ \\
\hline Role Functioning & 9.34 & 3.44 & 4.93 & 1.64 & $10.37 * *$ \\
\hline TOTAL & 147.28 & 26.19 & 76.42 & 16.58 & $20.45 * *$ \\
\hline
\end{tabular}

From Table 1 the t-ratio showed that there existed a highly significant difference between the total means of both the samples of discordant and harmonious wives on marital quality. The total mean scores of marital quality for both the

Volume 9 Issue 10, October 2020 


\section{International Journal of Science and Research (IJSR) ISSN: 2319-7064 \\ ResearchGate Impact Factor (2018): 0.28 | SJIF (2019): 7.583}

discordant and harmonious wives further explained that the scores were not only significantly different but also high in discordant wives $($ mean $=147.28$ ) than the harmonious ones $($ mean $=76.42)$. So the corresponding research hypothesis H1 was accepted with high statistical significance. The analyses confirmed that the perceived marital quality was poorer in discordant wives than that of the wives in harmonious marriage. Here also the subscale wise implicit hypotheses were found to be true. From the $t$ values of each of the twelve factors involved in marital quality indicated that the harmonious wives differed significantly from that of the discordant wives, in the areas where: they had good understanding in their marital unit, feeling of lesser rejection from their spouse, higher degree of satisfaction in sexual and security needs, fulfilled need for affection contributing to better concern and happiness, no feeling of despair due to a future relationship with full of hope, inclusion of the spouse in the decision-making process, absence of discontent due to perception of the spouse's ability to fulfill sexual and relationship needs, no consideration of being separated and divorced as an alternative (dissolution potential), lesser dominance of the spouse in their marital life, having good level of self-disclosure to their spouse, having able to obtain spouse's trust and adequate role functioning.

Table 2: Means (M), Standard Deviations (SD) \& t - ratios for the significance of difference between the two samples for the wives separately on P.C.S.

\begin{tabular}{l|c|c|c|c|}
\hline \multirow{2}{*}{ Groups } & \multicolumn{3}{|c|}{ Variable (P.C.S) } \\
\cline { 3 - 5 } & $\mathrm{M}$ & SD & t-ratio \\
\hline Discordant Wives $(\mathrm{N}=80)$ & 50.6 & 21.443 & \\
\hline & Harmonious Wives $(\mathrm{N}=80)$ & 110.26 & 14.574 & $20.583 * *$ \\
\hline$* \mathrm{p}<.01$
\end{tabular}

Table 2 represented the mean, standard deviation and t-ratios of Perception of Communication Satisfaction (PCS) scores of wives of both discordant and harmonious couples. From the tratio it became evident that there existed a highly significant difference between the means of both the samples of discordant and harmonious wives separately on Perception of Communication Satisfaction. The mean of each of the samples further explained that the Perception of Communication Satisfaction was not only different but also poorer in wives of discordant marriages than that of the harmonious marriages. So the corresponding research hypothesis $\mathrm{H} 2$ was accepted with high statistical significance.

The analyses confirmed that the perceived pattern of communication satisfaction was poorer in discordant wives (Table 2) than that of the wives who were in harmonious marriages. The gradual accumulation of day-to-day poor form perception of dissatisfaction related to communication play a significant role in the genesis of marital discord among the couples.
Table 3: Correlation Coefficient of P.C.S. (Total score) with M.Q.S. (twelve factors and total score) for the Total Sample

\begin{tabular}{|c|c|}
\hline \multicolumn{2}{|c}{$(\mathrm{N}=160)$} \\
\hline M.Q.S. Total & P.C.S. Total \\
\hline Understanding & $-.89 * *$ \\
\hline Rejection & $-.85 * *$ \\
\hline Satisfaction & $-.81 * *$ \\
\hline Affection & $-.78^{* *}$ \\
\hline Despair & $-.84 * *$ \\
\hline Decision Making & $-.76 * *$ \\
\hline Discontent & $-.84 * *$ \\
\hline Dissolution Potential & $-.68 * *$ \\
\hline Dominance & $-.70 * *$ \\
\hline Self disclosure & $-.32 * *$ \\
\hline Trust & $-.77 * *$ \\
\hline Role Functioning & $-.63 * *$ \\
\hline
\end{tabular}

** Correlation is significant at the 0.01 level.

From Table 3 it was found that all the factors of M.Q.S. and its total score were negatively and highly significantly correlated to the total score of P.C.S. So the corresponding research hypothesis $\mathrm{H} 3$ was accepted with strong confidence supported by high statistical significance. The analysis confirmed that the higher the scores on M.Q.S. (denoting lower marital quality), the poorer were the Perception of Communication Satisfaction and vice versa. In other words, the ladies who had poorer perception of communication satisfaction tended to have lack of understanding in their marital unit, feeling of grater rejection from their spouse, having lower degree of satisfaction in sexual and security needs, unfulfilled need for affection contributing to lack of concern and unhappiness, feeling of despair due to hopelessness and regret about the relationship, exclusion of the spouse from the decision-making process, discontent due to the spouse's inability to fulfill sexual and relationship needs, consideration of being separated and divorced as an alternative, dominance of the spouse in their marital life, having lower level of self-disclosure, having unable to obtain spouse's trust and feelings of inadequacy in role functioning. On the other hand, the ladies who perceived mostly a satisfactory feeling while maintaining the day-to-day communication with their spouses are those who scored low in marital quality scale denoting greater quality of marriage with their respective partners.

\section{Conclusion}

- The discordant and harmonious wives differed significantly in their quality of marital life.

- There were significant differences between the wives of discordant and harmonious groups in perception of communication satisfaction.

- Perception of communication satisfaction was significantly correlated with the perceived marital quality of both wives of discordant and harmonious marriage respectively.

Volume 9 Issue 10, October 2020 


\section{International Journal of Science and Research (IJSR) \\ ISSN: 2319-7064}

ResearchGate Impact Factor (2018): 0.28 | SJIF (2019): 7.583

\section{Limitations}

- As India is a diversified country with different religions, cultures and socio- economic status, the result of this study cannot be generalized.

- The general mental health, personality as well as the adjustment patterns of the persons were not considered.

\section{References}

[1] Amato, P. R. \& Rogers, S.J. (1997). A longitudinal study of marital problems and subsequent divorce. Journal of Marriage \& Family, 59, 612-624.

[2] Bradbury, T. N., Fincham, F.D., \& Beach, S.R.H. (2000). Research on the nature and determinants of marital satisfaction. A decade in review. Journal of Marriage \& Family, 62, 964- 980, DOI:10, 1111/j 1741-3737. 2000.00964.x.

[3] Daniel, G. (2006). Stumbling on Happiness (1st ed.), Alfred A. Knopf.

[4] DeMaris, A. (2000). Till discord do us part: The role of physical and verbal conflict in union disruption. Journal of Marriage \& Family, 62, 683-692.

[5] Goode, W. J. (1970). World Revolution and family patterns. New York: Free Press.

[6] Gottman JM. (1994). What predicts divorce? The relationship between marital processes and marital outcomes. Hillsdale, NJ: Lawrence Erlbaum.

[7] Hecht, M. L. (1978) The Conceptualization \& Measurement of Interpersonal Communication Satisfaction. Human Communication Research. Vol. 4, (3), Spring 19.

[8] Holden, L. (2008). Hindu divorce: A legal anthropology. London: Ashgate.

[9] Huston, T. L., Cauglin, J. P., Houts, R. M., Smith, S.E. \& George, L. J. (2001). The cannubial crucible: Newlywed years as predictors of marital delight, distress and divorce. Journal of Personality \& Social Psychology. 80:237-252.

[10] Jennings, E. (2014). Marital Discord \& Subsequent Dissolution: Perceptions of Nepalese Wives \& Husbands. Journal of Marriage \& Family, 76, 3, 476 -488.

[11] Karney BR, Bradbury TN. (1995)The longitudinal course of marital quality and stability: A review of theory, method, and research. Psychological Bulletin.;118:334. [PubMed].

[12] Mitra, S. Mukherjee, I. (2012). Adolescents' Satisfaction from Communication with their parents in relation to their state and trait aggression. Indian Journal of Community Psychology.Vol.8, Issue 1.

[13] Parry, J. P. (2001). Ankalu's errant wife: Sex, marriage \& industry in contemporary Chhattisgarh, Modern Asian Studies, 35, 783- 820.

[14] Shah, A. (1995) Clinical Validity of Marital Quality Scale, NIMHANS Journal, Vol. 13, (1), pp. 23-31.

[15] Spainer, G. B. \& Lewis, R. A. (1980). Marital Quality: A review of the seventies. Journal of Marriage \& Family, $42,825-839$.
[16] Yadav, K. \& Rakhee (2018). Exploring the attitudes of young adults towards marriage in India, IOSR Journal of Humanities \& Social Science, Vol. 23, Issue 3, Vers. 6, 25-44.

Volume 9 Issue 10, October 2020

www.ijsr.net

Licensed Under Creative Commons Attribution CC BY 